
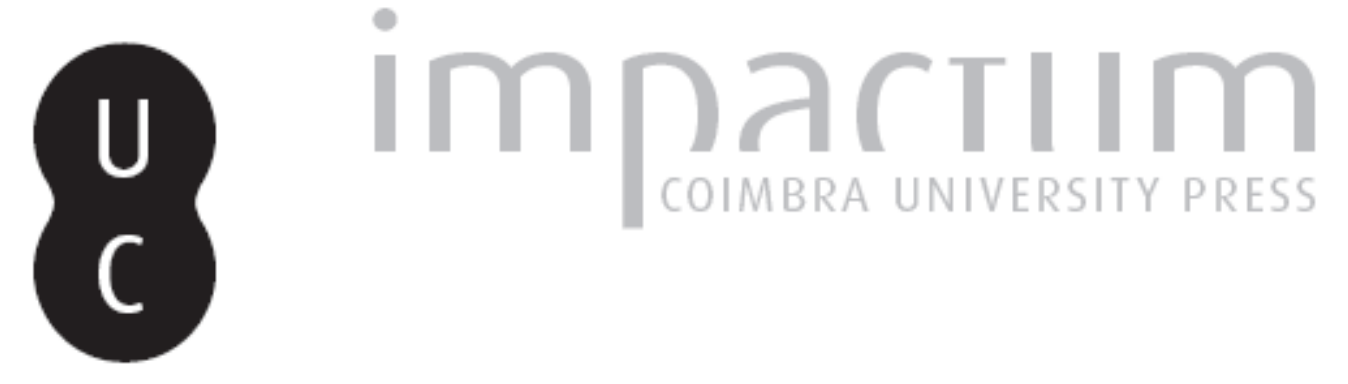

\title{
Meta_Body: uma investigação baseada na prática artística
}

Autor(es): $\quad$ Sousa, Catarina Carneiro de

Publicado por: Centro de Literatura Portuguesa; Imprensa da Universidade de Coimbra

URL persistente:

URI:http://hdl.handle.net/10316.2/37793

DOI:

DOI:http://dx.doi.org/10.14195/2182-8830_3-1_12

Accessed : $\quad$ 26-Apr-2023 15:20:26

A navegação consulta e descarregamento dos títulos inseridos nas Bibliotecas Digitais UC Digitalis, UC Pombalina e UC Impactum, pressupõem a aceitação plena e sem reservas dos Termos e Condições de Uso destas Bibliotecas Digitais, disponíveis em https://digitalis.uc.pt/pt-pt/termos.

Conforme exposto nos referidos Termos e Condições de Uso, o descarregamento de títulos de acesso restrito requer uma licença válida de autorização devendo o utilizador aceder ao(s) documento(s) a partir de um endereço de IP da instituição detentora da supramencionada licença.

Ao utilizador é apenas permitido o descarregamento para uso pessoal, pelo que o emprego do(s) título(s) descarregado(s) para outro fim, designadamente comercial, carece de autorização do respetivo autor ou editor da obra.

Na medida em que todas as obras da UC Digitalis se encontram protegidas pelo Código do Direito de Autor e Direitos Conexos e demais legislação aplicável, toda a cópia, parcial ou total, deste documento, nos casos em que é legalmente admitida, deverá conter ou fazer-se acompanhar por este aviso. 


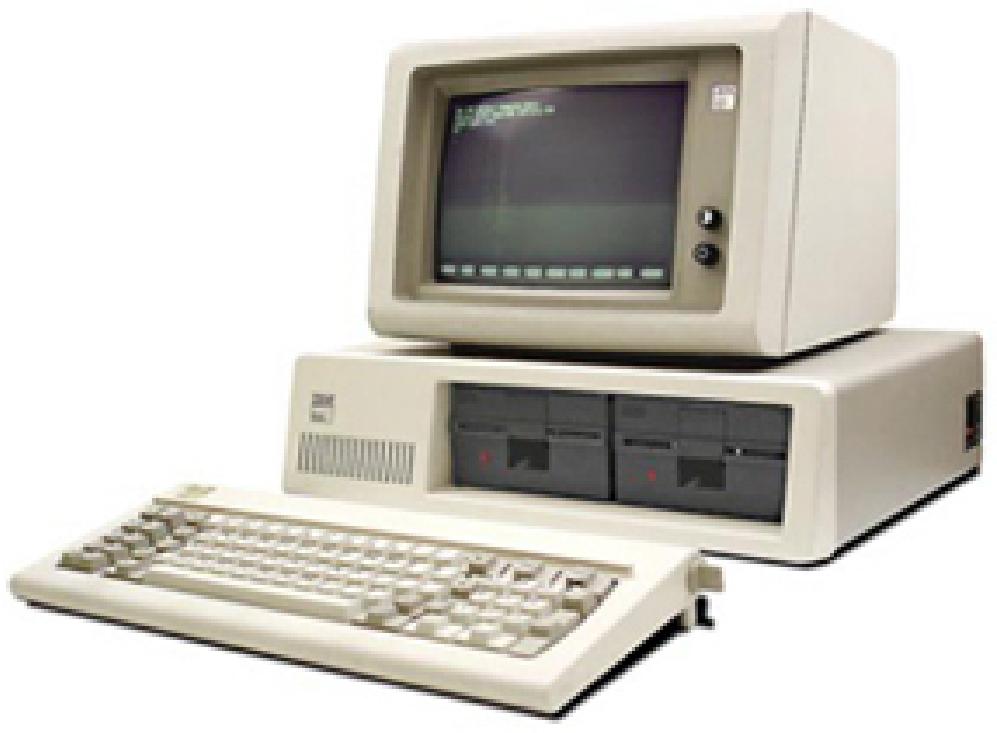

Vol. 3.1 (2015)

ISSN 2182-8830

'Artes, Média e Cultura Digital'

Paulo Silva Pereira e Pedro Serra (orgs.) 


\title{
Meta_Body: \\ Uma Investigação Baseada na Prática Artística CATARINA CARNEIRO DE SOUSA
}

\begin{abstract}
Resumo
Meta_Body é um projeto artístico participatório de construção de avatares, em desenvolvimento em ambiente virtual colaborativo. Trata-se de um projeto de investigaçãoação baseado na prática artística, uma vez que a abordagem teórica informa, mas também é informada pela praxis. Os principais eixos estruturantes da investigação são a constituição de uma corporeidade virtual e o processo criativo partilhado.
\end{abstract}

\section{Abstract}

Meta_Body is a participatory art project originating in the construction of avatars within a collaborative virtual environment. It is a practice-based research oriented towards artistic practice, since theoretical approaches inform practice, but they are also informed by praxis. The main lines of research concern the creation of a virtual corporeality and the shared creative process.

\section{Introdução}

[Meta_Body: https://www.youtube.com/watch?v=amlk38J-aDY]

eta_Body é um projeto artístico participatório de partilha e cons-
trução de avatares e outras obras derivadas, sediado no ambiente
virtual colaborativo da plataforma Second Life (SL) ${ }^{1}$. Este projeto foi iniciado por Meilo Minotaur (Sameiro Oliveira Martins) ${ }^{2}$ e CapCat Ragu (Catarina Carneiro de Sousa) em 2011 no Sim do SL ${ }^{3}$, Delicatessen, em resposta a um convite de Carla Cruz para a participação na $6^{a}$ edição da exposição All My Independent Women (AMIW). Foram concebidos dezoito avatares que continuam a ser partilhados com os participantes numa instalação virtual construída especialmente para o efeito em Delicatessen. Todos os avatares são distribuídos de forma aberta, isto é, com possibilidade de transformação,

${ }^{1}$ O Second Life é um ambiente virtual colaborativo, isto é, uma plataforma ambiental 3D multiusuário, em linha.

${ }^{2}$ Sempre que possível, referiremos os verdadeiros nomes de cada criador na primeira menção entre parênteses. No entanto, daremos primazia ao nome do seu avatar, uma vez que é esse, usualmente, o nome utilizado para assinar as obras.

${ }^{3}$ No SL, uma região corresponde a uma área de 256 m x 256 m de terreno virtual, hospedado por um único simulador. Normalmente, eles são referidos como Sims (Linden Research Inc. 2011). Delicatessen é o Sim concebido por Meilo Minotaur e CapCat Ragu. 
cópia e redistribuição. Junto com os avatares é, também, partilhada uma nota incentivando à participação no projeto através da conceção e partilha de obras derivadas. Numa primeira fase os participantes foram convidados a partilhar fotografias virtuais ${ }^{4}$ e machinimas ${ }^{5}$ para exibição na exposição, em ambiente físico tangível. 120 obras de 80 artistas foram apresentadas em Viena, na $6^{a}$ edição de $\mathrm{AMIW}^{6}$, em 2011. Numa segunda fase, iniciada em 2012, foi feito um novo convite à participação, desta feita na forma de avatares derivados, isto é, um novo conjunto de avatares concebidos a partir dos primeiros, para nova distribuição. Em 2013 Delicatessen reabriu ao público completamente reconstruída em quatro níveis, cada um dedicado a um grupo destes avatares derivados. Vinte e dois criadores, desde reconhecidos artistas e designers virtuais, até novos utilizadores, experimentando a construção no SL pela primeira vez, conceberam 26 novos avatares para distribuição aberta.

Para além de se tratar de um projeto artístico, Meta_Body também pode ser visto como um projeto de investigação-ação orientado e baseado na prática artística, uma vez que a abordagem teórica informa, mas também é informada pela praxis. A investigação orientada para a arte pode utilizar qualquer método de pesquisa cujo objectivo é informar uma prática artística, tanto do ponto de vista conceptual como técnico. Esta é uma perspectiva instrumental da investigação, que fornece instrumentos e conhecimentos necessários ao desenvolvimento de um determinado projecto (Borgdorff 2005).

A investigação baseada na arte parte do princípio que a arte pode ser vista como uma forma de representação e compreensão do conhecimento (Sullivan 2010, 56) e que, nesse sentido, as suas práticas e metodologias podem constituir uma alternativa ou complemento às formas tradicionais de pesquisa, expandindo, assim, o paradigma qualitativo da investigação (Leavy 2009, 3). Neste tipo de investigação há uma integração da pesquisa com a prática artística, tornando a última numa componente essencial tanto do processo de investigação como da apresentação de resultados (Borgdorff 2005).

Os principais domínios de investigação do projeto Meta_Body são, por um lado, a forma como se constitui uma corporeidade virtual e, por outro, os processos criativos partilhados em jogo neste projeto, desde a coautoria à

\footnotetext{
${ }^{4}$ No SL é possível, através do seu interface, capturar imagens fixas do ambiente virtual. O pictograma desta ferramenta é uma pequena máquina fotográfica. Entre os utilizadores é habitual referir as imagens recolhidas desta forma como fotografias.

${ }^{5}$ Machinima pode ser definido como a captura de imagens em movimento, em tempo real, usando motores de renderização em ambientes digitais 3D (Zagalo 2012, 2).

${ }^{6}$ AMIW teve lugar no espaço VBKÖ, Viena, mas entretanto o projeto Meta_Body já esteve patente em ambiente físico tangível (com diferentes adaptações) na Women's Art Library, Goldsmiths University of London; no Vox Feminae Festival, em Zagreb; na Brotherton Library Special Collections, University of Leeds; na $17^{\text {a }}$ Bienal de Cerveira; na Galeria Extéril, no Porto; no Colégio das Artes, Universidade de Coimbra; no Festival de Corporealidades Pós-Humanas, em Lisboa; e na Actividade - Artes Virtuais Interactivas Participativas, na Galeria Av. da Índia, em Lisboa.
} 
participação dos utilizadores. Vejamos como se integrou a investigação e a prática artística em cada um destes domínios.

\section{Corporeidade virtual}

O ponto de partida do projeto Meta_Body foi a seguinte questão, presente desde logo na chamada à participação na exposição AMIW:

A experiência do corpo em ambiente virtual não é exactamente uma experiência da carne. Pelo menos no que diz respeito ao avatar. Isto é, evidentemente muitas das experiências virtuais têm uma dimensão física, dos sentidos, mas estas sensações continuam a ser vividas nos nossos corpos por trás do monitor e não pelo corpo do avatar. O corpo virtual é um corpo metafórico. Um corpo todo linguagem. Como tal torna-se uma plataforma aberta à experimentação e à possibilidade.

Comecemos por compreender o que é um avatar na plataforma SL. Para Beth Coleman (2011) um avatar pode ser qualquer forma de extensão digital do sujeito que o presentifique em tempo real, síncrono ou assíncrono, na rede de telecomunicações - uma imagem de perfil numa rede social, uma mensagem de texto ou mesmo a sua voz. No SL essa extensão digital do sujeito é incorporada numa figura tridimensional gerada por computador. Este avatar pode tomar os mais diferentes formatos. A plataforma providencia uma ferramenta de personalização deste avatar que se baseia numa representação digital 3D da figura humana, com vários parâmetros que permitem ao utilizador transformar a configuração deste corpo, tanto nas suas dimensões e proporções gerais, como em aspectos mais pormenorizados como os formatos de nariz, olhos, boca, etc. Para além disto, essa figura (ou partes dela) pode ser tornada transparente e outros objetos digitais podem ser anexados ao seu esqueleto, permitindo transformar o avatar em qualquer objeto, animal ou criatura fantástica. 


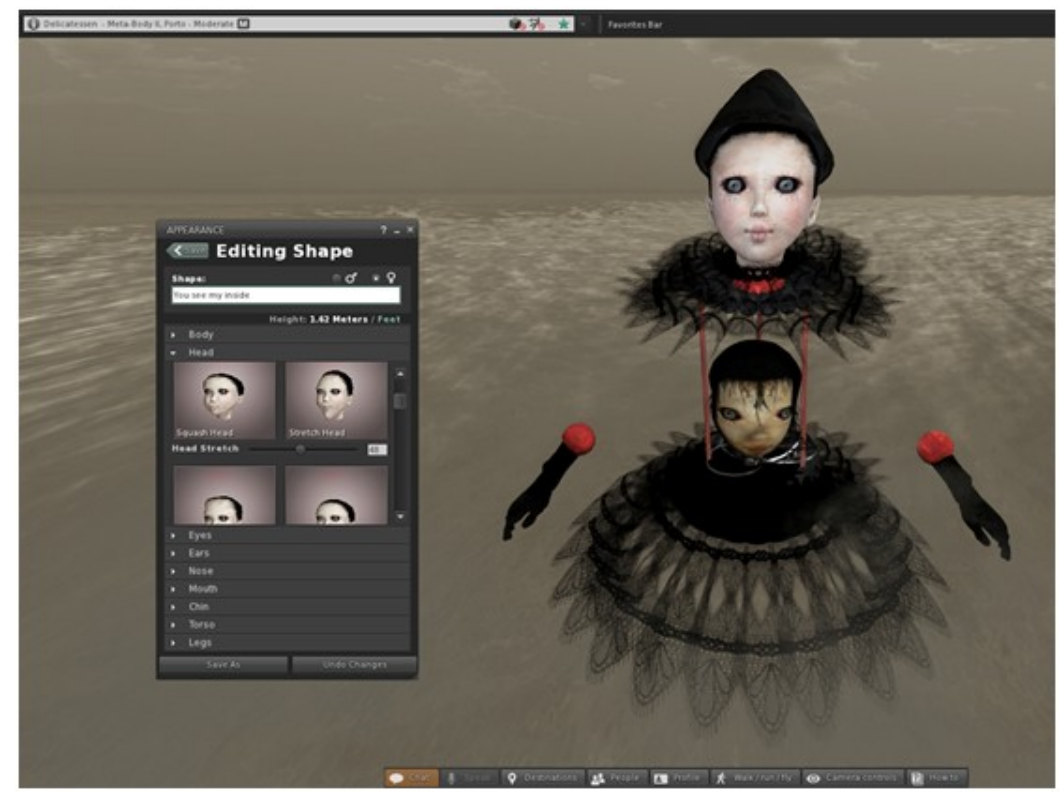

Figura 1. Captura de ecrã da plataforma Second Life, mostrando a personalização de um dos avatares da primeira fase do projeto Meta_Body, You see my inside, por Meilo Minotaur e CapCat Ragu, 2011. (C) Catarina Carneiro de Sousa.

Maeva Veerapen (2011) estudou a forma específica como incorporamos este avatar do SL e considera que existem dois corpos nesta plataforma, o corpo orgânico do utilizador e o corpo imagem do avatar, propondo quatro conceções do avatar: o avatar como objeto, o avatar como prótese, o avatar como membro fantasma e o avatar como igual. Na opinião de Frank Biocca (1997), a sensação de presença em ambientes virtuais só é possível porque o nosso corpo fenomenal nem sempre corresponde ao nosso corpo físico, isto é, a representação interna ou imagem mental que fazemos do nosso próprio corpo nem sempre lhe corresponde fisicamente. Veerapen tentou compreender como se constitui, então, este corpo fenomenal quando manipulamos avatares em ambientes virtuais colaborativos.

Para a autora a primeira forma de relação do utilizador com o avatar é enquanto objecto exterior, que lhe pertence e pode manipular. Nesta fase o avatar não tem impacto na constituição de um corpo fenomenal. Ainda assim, potencia desde logo a auto-expressão e a comunicação com outros utilizadores, da mesma forma que uma peça de roupa ou um acessório o pode fazer (Veerapen 2011, 89).

A segunda hipótese avançada por Veerapen é a do avatar enquanto prótese - o avatar funciona como uma extensão do corpo físico permitindo-lhe interagir com o ambiente virtual (Veerapen 2011, 89). No entanto, no SL é possível percorrer e observar o mundo sem usar o avatar, movimentando apenas o ponto de vista, sem que o avatar se mexa. Na realidade seria possí- 
vel total acesso ao mundo virtual sem avatar, poderíamos perfeitamente navegar como um "olho fantasma" completamente desmaterializado. Do mesmo modo que não são os olhos do avatar que vêem o mundo, também não são as suas mãos que manipulam objetos, de facto, estas ações são possibilitadas pelo interface da plataforma e não pelo corpo do avatar - é o interface, na sua totalidade e não apenas o avatar, que determina o impacto que podemos ter no mundo. A experiência prática de construção de objetos e ambientes evidencia esta questão. Ao construir temos tendência a retirar o avatar do nosso campo visual, uma vez que este não tem qualquer impacto na construção e pode mesmo tornar-se um empecilho.

A terceira conceção de avatar defendida por Veerapen é a do avatar enquanto membro fantasma. Nos membros perdidos por amputação é possível persistirem sensações, isto acontece por razões neurológicas que nada têm a ver com avatares e mundos virtuais, Veerapen utiliza este termo no sentido figurado. Ao contrário do membro amputado, o avatar nunca fez parte integrante do corpo do utilizador, ainda assim, a autora considera que pode despoletar sensações sem que haja um estímulo direto. Veerapen utiliza o exemplo de um ambiente visual em bambu sugerir o seu cheiro, activando a memória (Veerapen 2011, 91-92). No entanto, mais uma vez, neste caso o avatar poderia ser desnecessário. Visualizar o ambiente apenas, sem avatar, poderia desencadear o mesmo processo de ativação da memória.

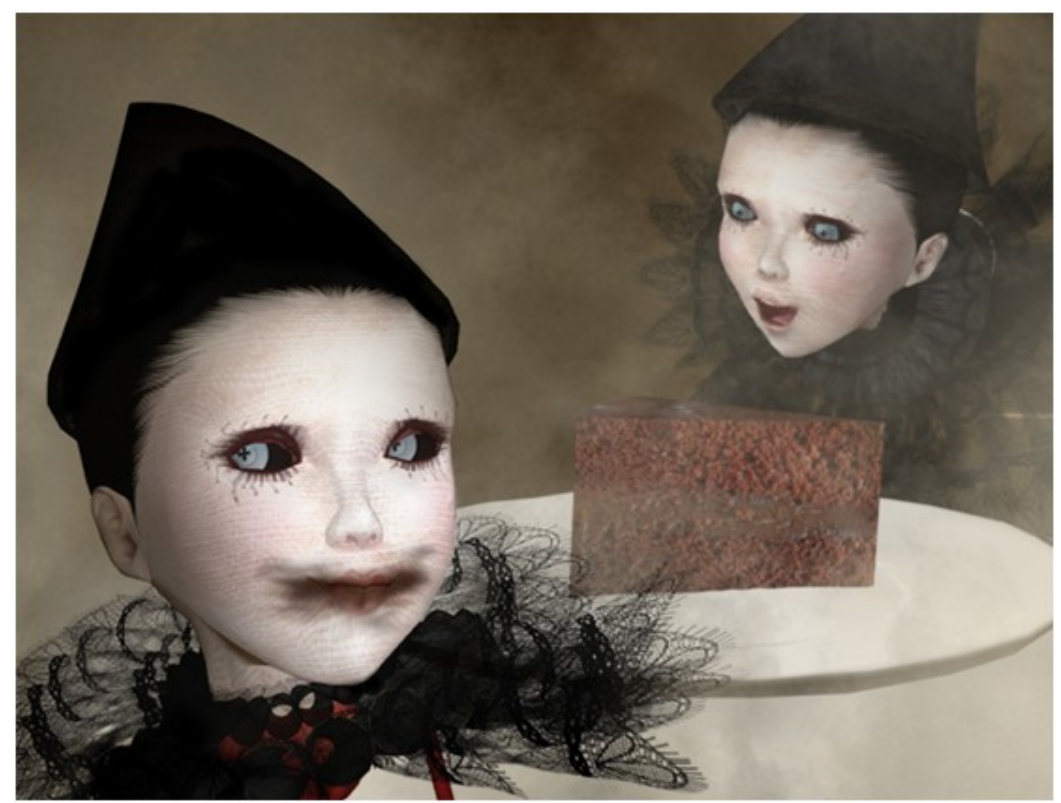

Figura 2. Let Me Have Cake, CapCat Ragu, 2015. (C) Catarina Carneiro de Sousa.

Todavia, alguns objetos virtuais estão associados a animações do avatar, permitindo que este interaja com eles, por exemplo, pedalando uma bicicleta, 
caindo num buraco, subindo uma escada. Não seria possível experimentar estas simulações sem usar um avatar. Um bolo digital muito realista pode fazer-nos salivar, ainda assim, se o nosso avatar o comer não lhe sentiremos o gosto. No entanto, esse gesto comunica visualmente envolvendo a nossa experiência corporal de forma metafórica. Não é possível experimentar mundos virtuais lendo-os a partir de linhas de código. Precisamos destas simulações visuais não só para interagir com mundo virtual, mas na verdade, para o conceber enquanto tal.

A quarta conceção de avatar de Veerapen é a do avatar como igual. Veerapen considera que, em ambientes virtuais, o corpo do utilizador, como não lhes tem acesso directo, não pode cumprir todas as tarefas de um corpo fenomenal. O corpo do avatar também não, já que lhe faltam as capacidades sensoriais ou percetuais. Para a autora o corpo físico e o corpo do avatar em simbiose cumprem todas as qualidades necessárias à constituição de um corpo fenomenal. Consideramos que a estes dois itens se deve juntar o restante interface da plataforma ${ }^{7}$. Como vimos, uma boa parte do acesso e impacto no mundo virtual passa mais por aquilo que é possibilitado pelo interface em geral, do que especificamente pelo avatar. Note-se que não se pretende com isto diminuir a importância do papel do avatar na relação com o ambiente virtual, na interação, e na constituição de uma corporeidade virtual, mas apenas lembrar que há aspetos deste processo que dependem de outras dimensões do interface. Como foi referido, a experiência de construção no SL demonstrou-nos isso mesmo. Por outro lado, a experiência de criação partilhada também nos mostrou a importância que o avatar pode ter a vários níveis.

$\mathrm{O}$ aumento de quantidade e qualidade dos estímulos sensoriais e motores na chamada interação incorporada tem sido visto como o principal meio de melhorar a qualidade da presença (Steuer 1993; Biocca 1997). No entanto, algumas investigações sugerem que ter uma representação visível de si próprio no ambiente virtual pode realmente aumentar a sensação de presença e a sensação de incorporação (Pearce 2009, 122). O avatar pode desempenhar um papel fundamental em algumas interações com o mundo que só se tornam percetíveis em termos metafóricos, referimo-nos especialmente àquelas que envolvem a animação ou outro tipo de transformação na aparência do avatar, que podem sugerir estímulos sensoriais de forma indireta — isto pode acontecer em todo o tipo de simulação de atividade física do avatar (e.g. a animação de movimentos, expressões faciais, etc.); simulação de impacto do mundo no avatar (e.g. responsividade da superfície do corpo à luz e sombra, do cabelo e tecidos ao vento e movimentos, etc.). $\mathrm{O}$ avatar pode assim

\footnotetext{
${ }^{7}$ Pode considerar-se o avatar como parte integrante do interface, já que "interface é um sistema ou dispositivo através do qual entidades não relacionadas podem interagir” (Sá 2010). No entanto, importa sublinhar que o avatar não é o único aspeto do interface que é relevante para a constituição de uma corporeidade virtual.
} 
potenciar uma sensação de presença corpórea. A manipulação, construção e partilha de avatares sublinha a o carácter simulado desta sensação.

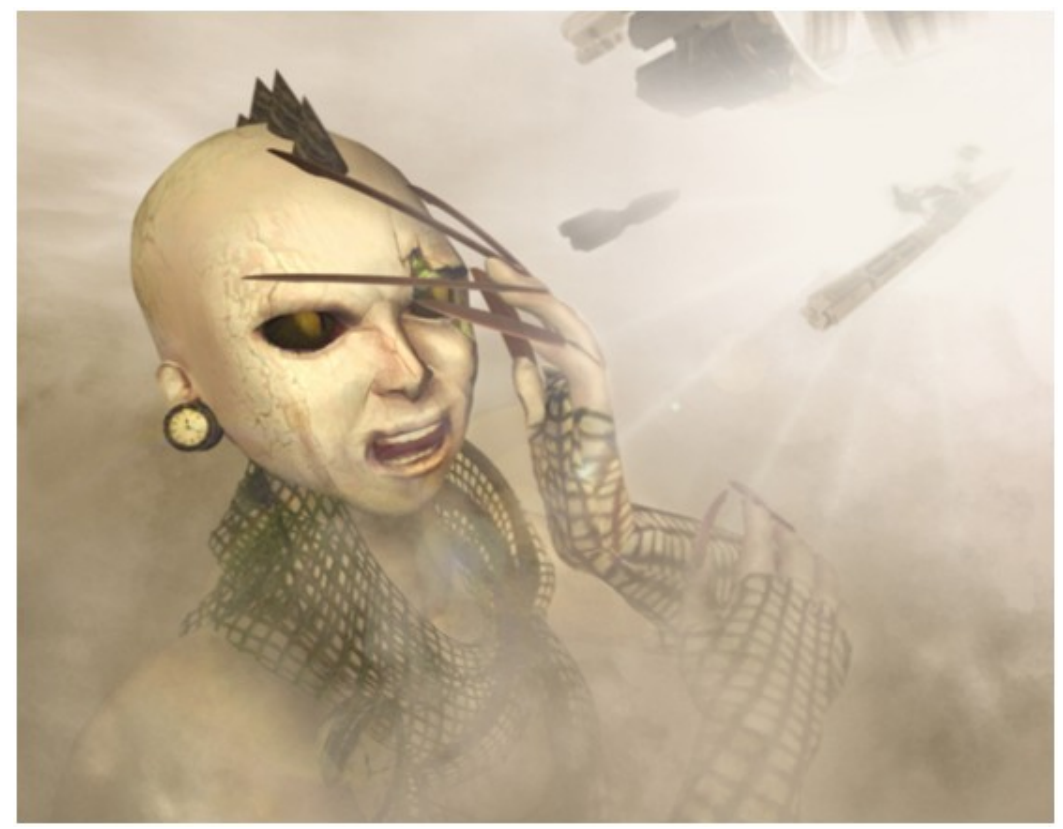

Figura 3. Lizard Apocalypse, CapCat Ragu, 2012. (C) Catarina Carneiro de Sousa.

No que diz respeito à comunicação com outros utilizadores, a sua forma verbal é, mais uma vez, relativamente independente do avatar ${ }^{8}$, já que tanto a utilização de texto escrito como de voz não dependem diretamente da utilização de um avatar, mas de outros aspectos do interface, como a possibilidade de utilizar janelas de texto escrito ou transmissão de voz; tanto de forma privada, como em grupos ou de forma pública (associada neste caso, à localização do avatar). O mesmo não acontece, todavia, com outros tipos de forma de expressão, onde se destaca evidentemente a expressão corporal. A possibilidade de controlo de gestos e expressões em ambiente virtuais como o SL é ainda limitada (apesar de aos poucos se estarem a desenvolver novas formas, mais intuitivas de o fazer) $)^{9}$. De uma forma geral os movimentos e expressões do avatar estão dependentes de animações predefinidas, que podem ser despoletadas diretamente, ativando uma animação arquivada; por um objeto com o qual o avatar interage, por exemplo, quando escolhemos sentar-nos numa cadeira esta pode estar programada para animar o avatar numa ou

${ }^{8}$ Neste caso, quando dizemos "avatar" referimo-nos especificamente à figura digital 3D presente em ambientes virtuais colaborativos, já que no sentido alargado de Coleman (2011) tanto texto como voz podem ser considerados avatares.

${ }^{9}$ São exemplo disso experiências que envolvem a utilização de dispositivos de captura de movimento como as experiências performativas participatórias Senses Places (Gomes, 2014) ou o ginásio virtual Open-Gym (Cassola, et al. 2013). 
várias posições; ou por um objeto anexado ao avatar e associado a um HeadsUp Display (HUD) ${ }^{10}$, que fornece um interface adicional relativo, neste caso, a uma compilação de animações, os mais usados são os Animation Override (AO), que permitem uma combinação de animações que criam uma expressão corporal personalizada, substituindo os movimentos standardizados da plataforma (andar, correr, saltar, voar, etc.) e os HUD de dança, que permitem animar, de forma sincronizada, vários avatares ao mesmo tempo.

Há estudos que sugerem que a expressão facial, postura corporal e gestos podem transportar de $60 \%$ a $90 \%$ da informação comunicada (Churchill e Snowdon 1998). Assim, para além da capacidade de movimentar o avatar poder contribuir para uma sensação de presença corpórea, a expressão corporal pode também ser essencial para a sensação de copresença, isto é a sensação de estar presente num espaço partilhado com os outros. Para Wijnand Ijsselsteijn e Giuseppe Riva (2003), existem três elementos principais que promovem este tipo de sensação de presença: a possibilidade de ação, um quadro cultural e a negociação tanto da ação como do seu significado (que liga os dois anteriores). Num ambiente partilhado, no entanto, isto implica não só um terreno comum de referências e regras (um quadro cultural), mas também a possibilidade de perceber as ações de cada participante. Para estas ações serem bem-sucedidas, é preciso entender a transição entre as acções comuns e as individuais, e isto requer tanto a comunicação explícita como a tácita entre colaboradores, assim como a capacidade de perceber o que está a ser e o que tem sido feito (Churchill e Snowdon 1998). A construção partilhada, ao longo deste projeto, não só de avatares, mas principalmente de objetos e ambientes, realçou estes aspetos fundamentais da copresença.

${ }^{10}$ Um HUD é uma forma de transmitir visualmente informações a um utilizador. No SL estes estão associados a scripts que alteram o comportamento ou aparência do avatar ou de objetos. 


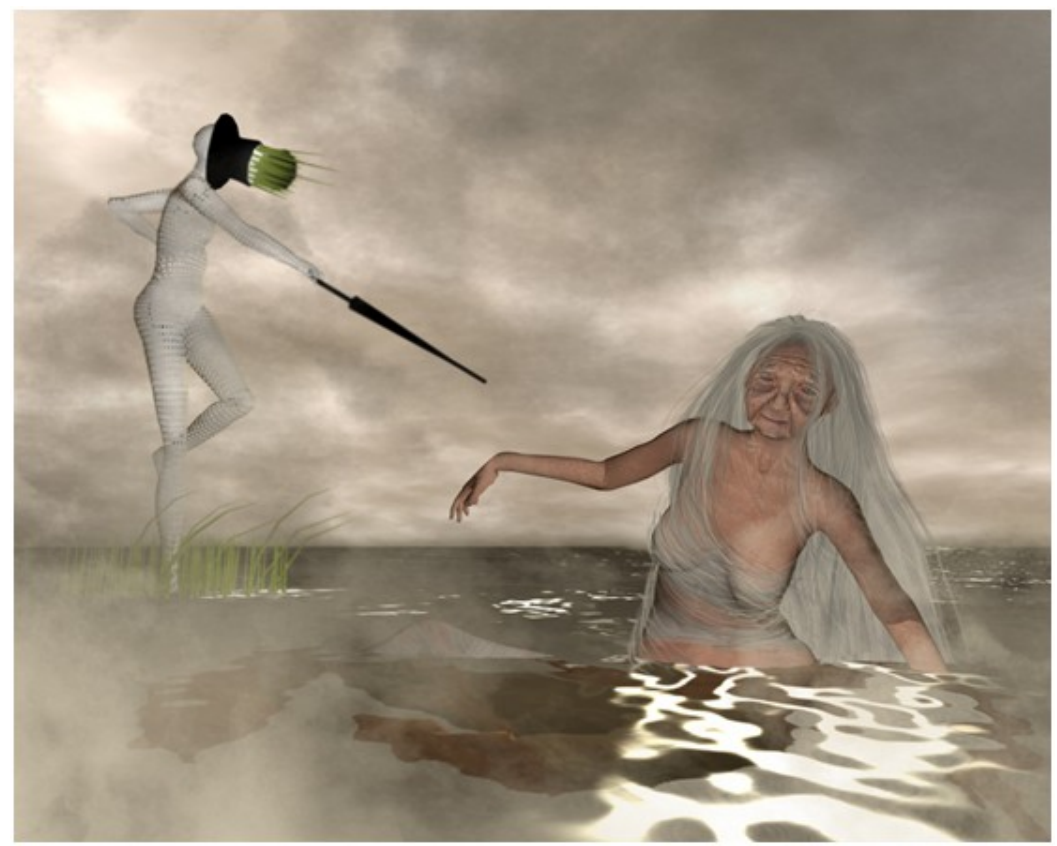

Figura 4. Untitled, CapCat Ragu, 2013. (C) Catarina Carneiro de Sousa.

\section{Criatividade partilhada}

Ao longo do projeto Meta_Body foram experimentados e estudados três tipos de processo criativo partilhado: a criação coletiva, a criação distribuída e a criação colaborativa (Sousa 2014).

Comecemos por distinguir o termo criação coletiva do uso comum da palavra coletivo, referindo-se a um grupo de pessoas que agem em conjunto de alguma forma. $\mathrm{O}$ que se pretende descrever aqui é um processo criativo particular, que de modo algum compromete outros diferentes e significativos aspectos da expressão coletivo. $\mathrm{Na}$ verdade um coletivo de arte não tem necessariamente de usar criação coletiva como um processo criativo. A intenção, neste caso, é referir um processo criativo no qual os participantes atuam como uma só entidade criativa.

A dissolução completa da identidade num grupo é uma utopia; um processo de cocriação, onde todos são parceiros iguais é muito difícil de alcançar em grupos grandes ou médios. Trabalhar como um só organismo plural (ou um monstro de várias cabeças) requer um alto nível de intimidade entre os cocriadores. Para existir verdadeira igualdade neste tipo de parceria, o sucesso é mais provável se esta for uma estrutura celular, em que cada um dos participantes renuncia à sua própria marca autoral em favor da autoria do grupo (CAE 2002). Portanto, criatividade coletiva é um processo desenvolvido por um pequeno número de cocriadores, que partilham um alto nível de intimidade. 
No caso deste projeto, este foi o processo preferido por Meilo Minotaur e CapCat Ragu tanto na construção dos avatares da primeira fase, como das instalações e ambientes virtuais. $\mathrm{O}$ facto de, na realidade, serem mãe e filha pode ter sido um fator fundamental para o sucesso do trabalho. Um processo coletivo de criação depende da capacidade de confiança total entre os intervenientes, não só no que diz respeito ao contributo artístico (é preciso confiar nas capacidades artísticas do outro), mas principalmente confiança de que a relação não vai desmoronar nos pequenos desentendimentos, nem na partilha frontal de ideias dissonantes (que por vezes tem de ser brutalmente honesta). Assim, este tipo de processo criativo pode beneficiar de relações particularmente íntimas, fortes e coesas, por outras palavras relações incondicionais.

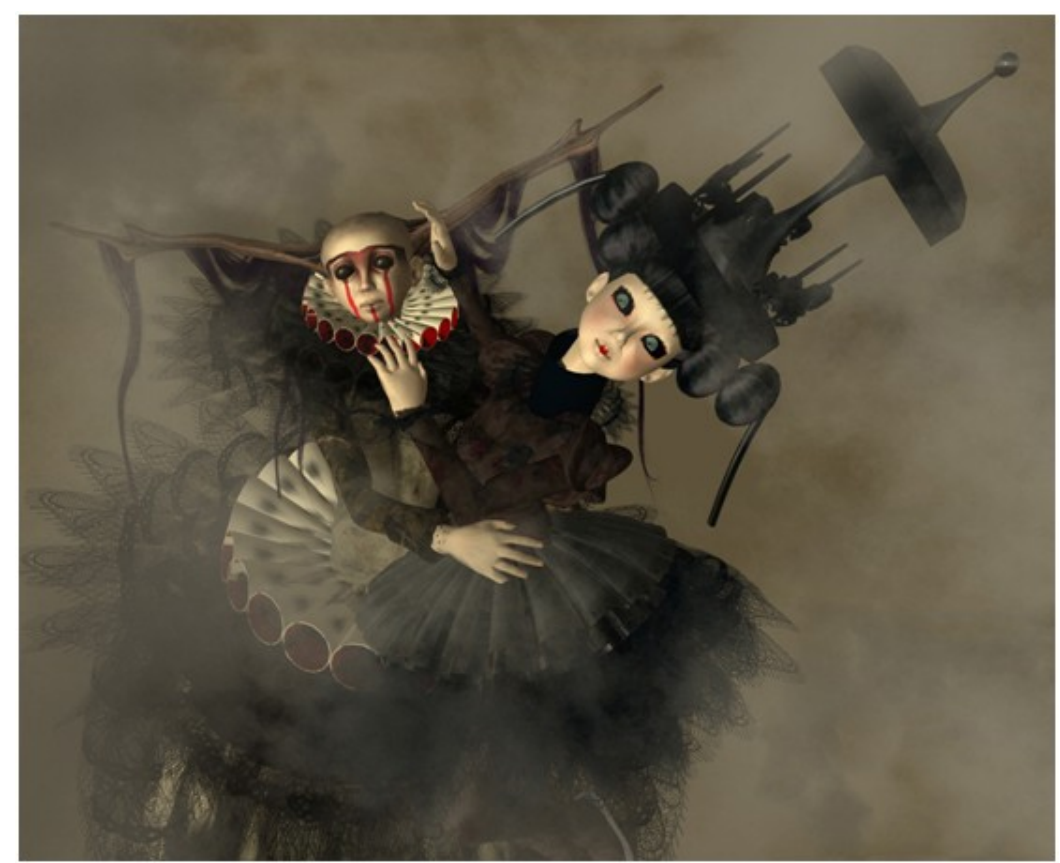

Figura 5. CapCat \& Meilo, CapCat Ragu, 2012. (C) Catarina Carneiro de Sousa.

A criação distribuída refere um processo criativo que depende de um grande número participantes, sem que estes, no entanto trabalhem enquanto equipa. Cada participante pode contribuir de diferentes maneiras (por vezes de forma totalmente isolada) para um fluxo criativo, sem ter obrigatoriamente que integrar formalmente um projeto, negociar os termos da sua prestação ou fazer parte de um grupo particular. Autoria distribuída foi um termo cunhado Roy Ascott em 1986 para descrever a autoria interativa e remota do projeto La Plissure du Texte: A Planetary Fairytale (LPDT) (Ascott 2005) e mais tarde usado por Axel Bruns para referir fluxos criativos capazes de aproveitar a criatividade de um vasto leque de participantes, que contribuem para 
expandir um conjunto determinado de material artístico (Bruns 2010, 1). Este autor desenvolveu também o conceito de produtilização para reconhecer a nova realidade emergente da Web 2.0 do conteúdo gerado pelos utilizadores (Bruns e Schmidt 2010, 3). Este termo define um modo de criação de conteúdos que é liderado pelos utilizadores, ou que pelo menos os envolve enquanto produtores de maneira fundamental (Bruns 2007, 4-5). Os produtilizadores podem participar de várias maneiras ao longo de um processo contínuo, de acordo com as suas competências pessoais, interesses e conhecimentos, alternando o seu papel entre utilizador e produtor, dando lugar à figura híbrida do produtilizador (Bruns 2007).

Os participantes do projeto Meta_Body podem ser considerados produtilizadores [cf. diaporama: https://vimeo.com/31369231]. Os avatares do projeto foram construídos e distribuídos de forma inteiramente gratuita, transformável, copiável e repartilhável, para a comunidade de utilizadores do SL. Meilo Minotaur e CapCat Ragu produziram conteúdo que outros utilizadores usaram para, por sua vez, produzir novos conteúdos que partilharam, e que foram depois utilizados para a exposição AMIW (no caso da fotografia virtual e machinima) ou para redistribuir em novas instalações virtuais (no caso do Meta_Body II com os avatares construídos pelos produtilizadores).

Maria Lind (2007) afirma que a palavra "colaboração" tem estado na ordem do dia no mundo da arte desde os anos 1990. Esta incorpora vários métodos de organização e uma ampla gama de processos criativos, sendo um "conceito aberto". Este termo acaba por referir os mais diversos métodos de trabalho que exigem mais de um participante (Lind de 2007, 17). O termo, aqui proposto, criação colaborativa não refere o termo colaboração nessa sua conceção aberta, mas tenta, antes, descrever uma maneira particular de criar em conjunto. Neste processo cada autor mantém a sua marca autoral e podese distinguir (ainda que por vezes vagamente) o trabalho de cada autor, mesmo que este se possa misturar, tornando difícil definir fronteiras. Este tipo de criação acontece muitas vezes como um diálogo entre autores, onde cada criação é uma resposta a outra criação.

A contribuição de Takio Ra para esta segunda fase do projeto foi desta natureza. Para distribuir os novos avatares derivados, Meilo Minotaur e CapCat Ragu construíram quatro instalações virtuais concebidas como homenagem aos avatares nelas alojados. Takio Ra compôs para cada um destes níveis as suas próprias paisagens sonoras, também estas fortemente inspiradas e evocativas dos materiais, estética e temas envolventes. Fragmentos de som foram espalhados em camadas pelos espaços virtuais, formando texturas sonoras contínuas, sequências melódicas ou composições assíncronas. Como no SL cada unidade de som é audível apenas dentro de um determinado raio da sua colocação, isso faz com que as paisagens sonoras mudem com o movimento do avatar através do espaço, criando assim uma experiência auditiva mais imersiva. Apesar do trabalho de Takio Ra não ter alterado formalmente as construções tridimensionais e se distinguir destas, contribuiu signi- 
ficativamente para a perceção deste espaço, transformando a forma como é experimentado [cf. https://www.youtube.com/watch?v=VEx9PVQT34k].

O projeto Meta_Body baseia-se, pois, num processo criativo a que chamamos de criatividade partilhada, em que não podemos reduzir a criação a um único autor. Vários componentes do projeto são construídos por diferentes autores e produtores, que trabalham no sentido de um corpo flexível, instável e sempre inacabado de trabalho. Um fluxo criativo alimentado por muitas correntes que atuam em vários momentos e a partir de diferentes processos criativos, cuja fluidez, com o tempo, se torna independente do controlo dos iniciadores do projeto, potenciando uma experiência estética da obra que se pode considerar criativa - a relação dos participantes com a obra pode estar para além da contemplação ou mesmo da interação, implicando, muitas vezes, uma apropriação criativa dos materiais distribuídos.

\section{Conclusões}

Conclui-se, assim, que a utilização de avatares em ambientes virtuais colaborativos pode ter importância na constituição de um corpo fenomenal, mas que não se pode esquecer que esta depende também do restante interface. A construção, manipulação e incorporação de avatares pode potenciar uma presença corpórea e esta sensação de existir materialmente no mundo virtual poderá ter uma dimensão metafórica. Estes aspetos teóricos da investigação alimentaram, mas também foram alimentados por uma prática artística.

O mesmo se pode dizer no que concerne à dimensão processual da obra, uma vez que desta emergiram três hipóteses de caracterização da partilha criativa - a criação coletiva, a criação distribuída e a criação colaborativa. A prática artística deste projeto também trouxe questões no que diz respeito àquilo que se pode considerar uma experiência estética no âmbito da arte contemporânea, sugerindo a possibilidade de uma dimensão criativa desta experiência.

\section{Agradecimentos}

A autora gostaria de agradecer dos seus colaboradores mais diretos Sameiro Oliveira Martins e Luís Eustáquio, assim como a todos os participantes deste projeto, que o tornaram possível e lhe deram significado. Gostaria ainda de agradecer as observações do Doutor Manuel Portela e da Doutora Elif Ayiter, fundamentais ao desenvolvimento desta investigação.

\section{Referências}

ASCOTT, Roy (2005). "Distance Makes the Art Grow Further: Distributed Authorship and Telematic Textuality in La Plissure du Texte." In At a 
Distance: Precursors to Art and Activism on the Internet. Ed. Annmarie Chandler and Norie Neumark. Cambridge: The MIT Press. 282-296.

BIOCCA, Frank (1997). "The Cyborg's Dilemma: Progressive Embodiment in Virtual Environments." Journal of Computer-Mediated Communication 3.2. http://jcmc.indiana.edu/vol3/issue2/biocca2.html (accessed April 23, 2012).

BORGDORFF, Henk (2005). "The Debate on Research in the Arts." Department of Political Science at the University of Gothenburg. http://www.pol.gu.se/digitalAssets/1322/1322713_the_debate_on_rese arch_in_the_arts.pdf (accessed January 8, 2015).

BRUNS, Axel (2010). "Distributed Creativity: Filesharing and Produsage." Ed. Stefan Sonvilla-Weiss. Mashup Cultures. Vienna: Springer. 24-37. (2007). "Produsage, Generation C, and Their Effects on the Democratic Process." Proceedings Media in Transition 5. Boston: MIT.

BRUNS, Axel, and Jan-Hinrik Schmidt (2010). "Produsage: A Closer Look at Continuing Developments." New Review of Hypermedia and Multimedia, 17.1: 3-7.

CAE (2002). "Collective Cultural Action: The Critical Art Ensemble." Variant 2, 15: 24-25.

CASSOLA, Fernando, Leonel Morgado, Fausto Carvalho, Hugo Paredes, Benjamim Fonseca, and Paulo Martins (2013). "Online-Gym: a 3D virtual gymnasium using Kinect interaction.” SLACTIONS 2013 - Research Conference on Virtual Worlds - Learning with Simulations. Elsevier.

CHURCHILL, E. F., and D. Snowdon (1998). "Collaborative Virtual Environments: An Introductory Review of Issues and Systems." Virtual Reality , 3: 3-15.

COLEMAN, Beth (2011). Hello Avatar: Rise of the Networked Generation. Cambridge: MA: MIT Press.

GOMES, Clara (2014). "Interactividade e Produtilização na Internet - o Caso da Ciberperformance." Artecapital. October 7, 2014.

http://www.artecapital.net/perspetiva-167-clara-gomes-interactividadee-produtilizacao-na-internet-o-caso-da-ciberformance (accessed December 12, 2014).

IJSSELSTEIJN, Wijnand, and Giuseppe Riva (2003). "Being There: The Experience of Presence in Mediated Environments." In Being There: Concepts, Effects and Measurement of User Presence in Synthetic Environments, by G. Riva, F. Davide and W.A (Eds.) IJsselsteijn, 3-16. Amsterdam: Ios Press.

LEAVY, Patricia (2009). Method Meets Art: Arts-Based Research Practice. New York: The Guilford Press.

LINDEN RESEARCH, Inc. Land. August 19, 2011.

http://wiki.secondlife.com/wiki/Land (accessed Agust 13, 2013).

PEARCE, Celia (2009). Communities of Play: Emergent Cultures in Multiplayer Games and Virtual Worlds. Cambridge: MIT Press. 
SOUSA, Catarina Carneiro de (2014). "Meta_Body — um projecto artístico de construção de avatares enquanto partilha criativa." Cultures-Kairós [online], Métamorphoses digitales: Expérimentations esthétiques et construction du sensible dans l'interaction bumain-machine, Théma. 07 21, 2014.

http://revues.mshparisnord.org/cultureskairos/index.php?id=886 (accessed July 21, 2014).

STEUER, Jonathan (1993). "Defining Virtual Reality: Dimensions Determining Telepresence." cybertherapy. October 15, 1993.

http://ww.cybertherapy.info/pages/telepresence.pdf (accessed February 11, 2014).

SULLIVAN, Graeme (2010). Art Practice as Research: Inquiry in Visual Arts. London: Sage.

VEERAPEN, Maeva (2011). "Encountering Oneself and the Other: A Case Study of Identity Formation in Second Life." In Reinventing Ourselves: Contemporary Concepts of Identity in Virtual Worlds (Springer Series in Immersive Environments), by Anna Peachey and Mark (eds.) Childs, 81-100. London: Springer.

ZAGALO, Nelson (2012). "Machinima: A Creative Technology." November 15, 2012. http://www.slideshare.net/nzagalo/machinima-a-creativetechnology (accessed March 28, 2014).

(C) 2015 Catarina Carneiro de Sousa. Licensed under the Creative Commons Attribution-NoncommercialNo Derivative Works 4.0 International (CC BY-NC-ND 4.0). 